En la carta 12 se encuentra tal vez el mejor ejemplo de humor en un juego lúdico memorable. Ella le cuenta a Rodolfo sobre una traducción que está haciendo de un libro cuyo texto es "una solemne porquería" (59) pero que si embargo, "los héroes del libro son los animales de la selva del Amazonas, y, ellos sí que son maravillosos” (59). A ella le llama la atención especialmente una Rana Cornuda Gigante que es tan fea que parece venir de otro mundo y “iEs divina!” (59), dice. Le sorprende que la rana tenga la pupila de los ojos de forma rectangular; luego exclama: "Si usted no existiera, me haría traer la rana, le pondría Casa, y me casaría con ella. Y la llevaría a pasear por la Reforma y otros lugares elegantes, con el cuello aprisionado por una cadenita de oro torcido, y los cuernos llenos de diamantes rosa" (60). Ella se imagina, regocijada, la admiración que tal espectáculo produciría entre el público, pero también en tono de burla, piensa en la vergüenza que sentiría su familia. Sin embargo, el aspecto más interesante de este segmento es que remite directamente a una anécdota cómica que se cuenta de Gérard de Nerval al cual en una ocasión se vio paseándose por los jardines del Palais-Royal en Paris con una langosta viva, su mascota, Thibault, sujeta por una cinta azul (Apollinaire, G., "La vie anecdotique". Oeuvres en prose complètes. En P. Caizergues y M. Décaudin (Eds.), 1988, p. 75).

Antes de dar fin a este vistazo de la excelente edición de Jorge Chen Sham a Cartas de Eunice Odio a Rodolfo, es necesario mencionar cuánto revelan estas misivas la intensa capacidad de amar de Eunice Odio. La imagen de Rodolfo Zanabria aparece siempre rodeada de una plétora de apelativos saturados de afecto. Él es su "osito mío", "amadísimo pintor" (60). Este afecto se extiende a amigos de la calidad de Juan Liscano, quien es a veces su "chiquito mío" (Liscano, 1975, p. 77); también el amor se desborda hacia los animales que para ella son "Unas criaturas llenas de gracia, inteligencia, belleza física y moral" (59). Todo este afecto se manifiesta como una suerte de amor maternal innato que cubre a sus seres amados.

Jorge Chen Sham ha hecho bien en publicar esta correspondencia tan fielmente documentada. Ella servirá para que se produzcan más estudios sobre la obra y la figura humana de la singular Eunice Odio. Si alguien ha obrado mal sacando a luz estas cartas, el único culpable habrá de ser el destinatario, el pintor mexicano Rodolfo Zanabria que tanto pesar le causó a la poeta.

Cida S. Chase

Oklahoma State University

\title{
Felipe Gómez Gutiérrez y María del Carmen Saldarriaga (Eds.). Evelio Rosero y los ciclos de la creación literaria. Bogotá: Pontificia Universidad Javeriana, Opera Eximia, 2017, 272 páginas
}

Escribir sobre Evelio Rosero ha significado un reto mayor, que comparto con entusiasmo y reconocimiento en mi lectura, esperando se propague el espíritu del libro que reseño: celebrar la obra narrativa de Evelio Rosero a través de la crítica literaria, expresando y develando sentidos que alternan voces y gestos literarios. El libro se titula Evelio Rosero y los ciclos de la creación literaria (2017), editado por Felipe Gómez Gutiérrez y María del Carmen Saldarriaga, investigadores que han dado vida a un texto valioso, publicado en la Pontifica Universidad Javeriana, en Bogotá. La portada identifica la fotografía del rostro de Rosero con la mirada fija, de modo que su rostro está construido por varias fotos que dividen el paisaje y la realidad colombiana. 
Considero que este texto será un punto de partida para estudiar y leer su narrativa en Latinoamérica, puesto que su obra ha tenido mayor recepción en otras partes del mundo que en su natal Colombia. Los editores apuntan el silencio de la crítica en Colombia previo a este loable esfuerzo: "Su respuesta, inusitadamente a la abrumadora, nos confirmó que el silencio crítico sobre la obra del autor no era más que la carencia de un medio de difusión que se prestara a coordinar esfuerzos particulares en un objetivo en común" (11). Este es un libro propositivo, que rodea las visiones en una excelente presentación; además de la pluma de los ensayistas, accedemos a una entrevista con el autor, que propone una antesala a la interpretación académica: ““'Soy una consecuencia literaria de mi país”: conversación con Julia Martínez y María del Carmen Saldarriaga con Evelio Rosero". El escritor evidencia su “desesperación” por la violencia, así como el proceso de escritura, sus anécdotas, sus silencios, integrando lo humano mediante sus memorables personajes: "Esto es, queríamos que el autor del que tanto íbamos a hablar tuviera "primero la palabra"" (29), lo que brinda un equilibrio al quehacer de la crítica. También se incluye al final, la bibliografía de su obra (1984-2017) y sus premios. Evelio José Rosero Diago (Bogotá, 1958) ha escrito novela, cuento, poesía, teatro y ensayo; ganó el Premio Nacional de Literatura en 2006, a lo que continúa Los ejércitos (2007), momento en que su reconocimiento trasciende allende las fronteras y recibe el premio Tusquets Editores; con una amplia producción desde Mateo solo (1984), Los almuerzos (2009), La carroza de Bolívar (2012), último texto con el que obtiene el Premio Nacional de Novela en 2014, y una larga lista de obras hasta Toño Ciruelo (2017). De un modo coherente en el título se evocan "los ciclos" como una forma geométrica que delinea y expande momentos claves, momentos que se reiteran, y que en su entrevista Rosero nombra varias veces: "El Evelio Rosero que leemos hoy en día, es entonces, uno que se repite constantemente en forma cíclica, más en espiral. De sus cuentos nacen sus novelas, de sus novelas surgen los personajes adultos de otras más que luego se convierten en niños y regresan a los cuentos. Este tránsito no surge de un escenario narrativo sino de un personaje" (17).

Las publicaciones de libros de crítica literaria respiran a través del ensayo y sus posibilidades teóricas y reflexivas. El objetivo es colocarse en lo "central" de la obra, pero así también desplazarse hacia otras miradas, reconocidas o ajenas al escritor, a su estilo, y a su lugar dentro de la crítica hispanoamericana. Los investigadores editan de una manera valiosa este libro y nos comunican su conocimiento privilegiado del autor al identificar temas claves, sobre todo, relacionados con los desaparecidos, la poesía, el cuerpo y la enfermedad, lo gótico, la novela histórica, así como varias aproximaciones interpretativas a la novela de Los ejércitos, y finalmente, encallan en la narrativa infantil. El hincapié de las miradas se sitúa en un tema relacionado con la memoria, la identidad y la construcción del mundo dentro del relato: "Rosero no trabaja con estos personajes la idea de la identidad, ni nacional ni personal; para él, la identidad, entendida como algo que cohesiona al sujeto fragmentado, es tan mitológica que tal vez no tenga origen en la realidad. No hay elementos en el mundo, por arcaicos y primigenios que sean, que la representen o sustenten" (17).

En mi lectura se han acumulado conceptos para analizar las constantes, representaciones, ciclos, tradiciones en la narrativa y la poesía de Rosero. De este modo, apreció una radiografía de la profundidad y la densidad al detenerme en algunos trabajos que me han brindado la reconstrucción de la memoria del olvido, y me han propuesto una estructura a través de la argumentación y la fluidez del libro mismo. En el primer apartado, "La obra como senda: estéticas, espacios y representaciones", el primer texto titulado “"'La mirada sin perspectiva de 
la niebla": antología y desaparición en En el Lejero", de Juliana Martínez, que inicia de una manera tajante en relación con la violencia en Colombia, los secuestrados y los desaparecidos al confrontar la memoria histórica, el espacio, la geografía y la gramática de la violencia: "De 1998 a 2002, la época de la escritura de la novela, el número de secuestros alcanzó su punto más alto al superar los tres mil secuestros anuales, es decir, más de ocho al día" (43). La tesitura de este ensayo me lleva a pensar en la reconstrucción de la memoria desde los cuerpos ausentes: “...sin restos, sin epitafio, sin duelo; una desaparición que se pensó a sí misma sin huella, total” (52). Según esta investigadora, Rosero invita a pensar y trastocar "la crisis de la representación (política, conceptual, estética) producida por la violencia" (54); esto a través del concepto de Espectro de Derrida. Sigue el texto, "Razón, sublimidad, desposesión: El gótico de Evelio Rosero en Los almuerzos", de Julio Quintero. Otro ensayo revelador fue la "Enfermedad, cuerpo e institución en la producción narrativa de Evelio Rosero", de María del Carmen Caña Jiménez, donde se explora la corporalidad y la enfermedad en Los ejércitos, La carroza y En el Lejero, aquí se detiene de manera puntual en cómo la enfermedad incide en el "cuerpo individual (como espacio dialógico) y el cuerpo social (más específicamente, la nación)" (79). Este ensayo revisa a profundidad un análisis que devela "las máscaras de la Historia", discurso del cual Rosero aprovecha para reconstruir la memoria colectiva a través de las imágenes corporales y las enfermedades como el cáncer, la tuberculosis y la locura desarticulando los cuerpos y nombrando el dolor, continuidad del silencio y la violencia. La primera sección cierra con el excelente texto, "La mirada del Flâneur y los motivos de la tarde/ noche en los primeros poemas de Las Lunas de Chía", de Jorge Chen Sham; trabajo que revive el placer poético de la figura del voyerista y del cuerpo femenino a través de la noche, la luna, y la luz transfigurada en deseo y soledad. Ensayo que recupera el gozo de la palabra y divaga en las galerías de la poesía: "El flâneur se pone en la perspectiva de la periferia, la diferencia y la marginalidad para mirar con simpatía a los que son desfavorecidos" (97).

En el segundo apartado, "La encrucijada del estilo: Novela histórica o historia ficcionalizada", se inicia un recorrido que identifica la narrativa de Rosero en torno la novela histórica y la desmitificación de figuras emblemáticas: "La carroza de Bolívar: entre la verdad histórica y la verdad novelesca", de Iván Vicente Padilla Chasing; "En nombre de la memoria: los oficios del recordar en Los Ejércitos y La Carroza de Bolívar", de Caroline Hounde; "La obra de Evelio Rosero y la reinscripción de la historia", de Cecilia Caicedo Jurado. Esta sección, bien cuidada, gira en torno a varios conceptos que cuestionan el discurso histórico oficial, atribuyendo caminos alternos dentro de la ficción y cuestionando los usos de "lo histórico" en el presente de la producción textual del autor, entre la memoria colectiva y la falta de memoria. La pregunta: ¿qué es una novela histórica?, según Padilla Chasing en su profundo texto, se responde de la siguiente manera: "Una novela no es histórica por el hecho de introducir situaciones y personajes históricos, sino por la forma de tratarlos" (118); dice el mismo ensayista: "Rosero se decide por una narrador-contador-reconstructor de la memoria, cuya mirada recae no tanto sobre lo sucedido (historia), sino sobre aquello que no sucedió porque fue menospreciado, deliberadamente ignorado en el proceso cientista-historicista" (119120). Del mismo modo, en "Ecos críticos sobre Los ejércitos", se sigue la trayectoria de una de las novelas más leídas de Rosero: "'Ahora nos toca a nosotros": fantasmas y violencia en Los ejércitos", de Alberto Fonseca; "Erotismo, obscenidad y abyección de Ismael Pasos en Los ejércitos", de Carlos-Germán van der Linde; y "Derechos humanos, sujeto liberal y empatía en Los ejércitos", de Carlos Gardeazábal Bravo; de hecho, este último texto alude al tratamiento 
de una narrativa que trabaja con la "empatía, los traumas y derechos humanos", involucrando ideas en torno a las "reflexiones corporeizadas" y a "una fenomenología encarnada, corpórea": "La invitación de Rosero a su lector a llevar a cabo el "desasosiego empático" de La Capra se enfatiza en ese silencio, como una forma de lograr el reconocimiento respetuoso de la diferencia entre la pérdida del otro y la propia, de modo que crea una empatía reflexiva y evita la cosificación del dolor de las víctimas" (206-207).

En el último apartado, "Literatura transparente: narrativa infantil y juvenil”, se concluye con dos ensayos: "La literatura transparente de Evelio Rosero: ¿Liberación de la mente o huida de la realidad traumática", de Polina Golovátina-Mora y Ana María López Carmona. Este delicado trabajo me devela una propuesta que no simplifica la literatura infantil: "La violencia resultante se resume en diferentes formas, como en la pelea en "El monstruo mentiroso" [...] se manifiesta la muerte metafórica del alma, como una consecuencia de la pérdida de los sueños y de la elección de un camino diferente, o en la ausencia de entendimiento y de compañía en el orden social, como ocurre, por ejemplo, en El aprendiz de mago, la duenda y La princesa calva. El reemplazo del ser vivo por un objeto ayuda a resaltar lo absurdo de la violencia" (220-221). Finalmente, "Un escultor de transparencias: la figura de la infancia en la novelística temprana de Rosero", de María del Carmen Saldarriaga, cierra en un perfecto tono de reencuentro con la narrativa de este autor.

En total es un conjunto de doce ensayos que abordan la construcción estética y la reconstrucción histórica en sus novelas. Afirman los editores: "Como lo sugerirá la lectura de estos ensayos, para mediar entre la dicotomía entre la tradición y la modernidad, Rosero recurre a la memoria como pieza de su poética" (18). La reconstrucción de la memoria del olvido sugiere, según lo intuyo, una necesidad de reconstruir la realidad social e histórica para ubicar el silencio y el olvido, es decir, de aquello que no se nombra, lo que se deja fuera de la historia oficial; se propone enunciar los intersticios que puedan transmutar lo vivido en un halo mágico. En este tenor creo que la literatura infantil de Rosero, "la literatura transparente", es una forma armoniosa y amorosa de afrontar la violencia real; en mi percepción el que sea infantil no garantiza la transparencia -mediada por la ficción-, más bien pienso que es la única manera de recrear con vitalidad y sorpresa todo aquello que se olvida, que se calla por miedo, por no saber cómo nombrarlo; esta "memoria del olvido" que los ensayistas rescatan, de una forma o de otra, y que el mismo Rosero logra al "evidenciar y dignificar" en el uso de la palabra hacia una verdad que sigue el camino de la imaginación; a final de cuentas esta verdad "transparente" resignifica lo humano. El camino de Rosero, según lo advierto, atraviesa una prosa poética y una memoria poética para dignificar "los significados" de la paz que florecen en cada lector al compartir sus novelas, sus cuentos y poemas; por lo que afirmo que la literatura infantil no es un género menor, en absoluto, pues al concluir este libro de crítica literaria todo adquiere sentido, entonces uno podría empezar a leer los primeros ensayos desde otro ángulo.

Escribo desde México, lo que me permite expandir un tiempo y un espacio. Escribo desde un ritmo de lectura que intenta transmitir la mirada de otros lectores especializados, de quienes he aprendido a partir de sus subjetividades y textualidades de la obra de Rosero, pero no puedo evitar posicionarme desde mi subjetividad geográfica. Escribo desde la violencia mediatizada, la violencia real, la violencia de género, la violencia que genera miedos y olvidos, la violencia hacia sí mismos/as. Mi país ha sufrido la violencia de manera cotidiana desde hace varios años, "México se colombianizo". Las generaciones olvidan, y ante la ausencia de la memoria es necesario rescatar la memoria del olvido y del silencio que han dejado las 
diferentes atrocidades humanas. La literatura de Rosero es una voz poética para la paz, porque es imposible evadirse de una "intuición imaginativa", de "escribir contra viento y marea", cuando "nunca ocurre lo que yo premedito; eso es lo mágico de escribir. Sin fórmulas", frases que sostiene en su entrevista.

Los editores agradecen a los ensayistas que se reúnen para evadir el silencio de la crítica literaria en Colombia, dignos de elogiarse por su calidad y el tono riguroso de la mayoría de los textos; agradece Rosero la entrevista, y a los lectores; agradezco yo también el privilegio de reseñarlo, pues es un autor que no me era tan cercano como lo siento ahora. Entre la controversia y el vértigo, me propongo compartir este autor con mi hija (quien ha leído cuentos infantiles de Clarice Lispector); ahora podemos leer juntas el Aprendiz de Mago y otros cuentos de miedo (1996), para atravesar los ciclos de la creación literaria, en una íntima conexión con la narrativa de Evelio Rosero.

Elsa Leticia García Argüelles

Universidad Autónoma de Zacatecas

\section{Brigitte Adriaensen y Marco Kunz (Eds.). Narcoficciones en México y Colombia. Madrid/Frankfurt: Iberoamericana/Vervuert, 2016, 258 páginas}

La representación del narco y sus redes tentaculares han invadido no solo los productos masivos de la cultura, sino también ha permeado la narrativa latinoamericana para quedarse. Ya no puede ser considerado un epifenómeno como tampoco una tendencia que marca una literatura de corte popular y de ratings audiovisuales; es ya objeto de investigaciones académicas como el libro que reseñaremos a continuación. En la "Introducción" (9-24), firmada por Brigitte Adriaensen, se comienza apuntando esa extrañeza y malestar de que el narcotráfico irrumpe, con sus tentáculos de poder y de violencia, en los imaginarios culturales; se trata de un tragedia de orden social o de la justicia ligada al flujo y a redes internacionales, más allá del reduccionismo estereotipador de que sea un problema endémico de Latinoamérica. Ahora bien, Adriaensen plantea el término de "narcoficciones", para designar aquellos productos culturales, cine, música, telenovelas, teleseries o literatura que "versan sobre el narcotráfico" (11). Su impacto cultural y mediático se observa desde los narcorridos mexicanos de los Tigres del Norte o Los Tucanes de Tijuana, hasta las teleseries como El cartel de los sapos (2008, Caracol Televisión) a Pablo Escobar, el patrón del mal (2012, Caracol Televisión), en donde se reivindica la figura del "narcotraficante" (12). Estas producciones seriales se cuestionan porque no ofrecen una perspectiva más antropológica o de crítica incisiva a ese "espectáculo de la violencia" (13). Este balance inicial, Adriaensen lo complementa con el cine, en donde películas como la colombiana María, llena eres de gracia (2004) o la mexicana Miss Bala (2011) abordan la cuestión humana del narcotráfico y la inmigración; pero no superan los circuitos de festivales, mientras la "narconovela" apenas se vende, en detrimento de los reportajes periodísticos y crónicas como la de Carlos Castaño, Mi confesión (2001), la cual vendió más de 110000 ejemplares (15).

Estereotipos abundan, como aquel relacionado con la preeminencia de la narcoliteratura en el regionalismo norteño mexicano, o con la "representación estereotipada y a veces banalizada de la violencia" (15), a lo que hay que agregar también una "despolitización" o una "fetichización de la figura del narco". Ante este panorama se impone un discurso más analítico que estudie las relaciones centro-periferia en el caso mexicano, o la experiencia de 